\title{
Characterization of $\mathbf{N}$-Acetylglucosamine Biosynthesis in Pneumocystis species
}

\section{A New Potential Target for Therapy}

\author{
Theodore J. Kottom ${ }^{1}$, Deanne M. Hebrink ${ }^{1}$, Paige E. Jenson ${ }^{1}$, Jorge H. Ramirez-Prado², and Andrew H. Limper ${ }^{1}$ \\ ${ }^{1}$ Thoracic Diseases Research Unit, Departments of Internal Medicine and Biochemistry and Molecular Biology, Mayo Clinic College \\ of Medicine, Rochester, Minnesota; and ${ }^{2}$ Unidad de Biotecnologia, Centro de Investigacion Cientifica de Yucatan, Asociación Civil, \\ Merida, Yucatan, Mexico
}

\begin{abstract}
$\mathrm{N}$-acetylglucosamine (GlcNAc) serves as an essential structural sugar on the cell surface of organisms. For example, GlcNAc is a major component of bacterial peptidoglycan, it is an important building block of fungal cell walls, including a major constituent of chitin and mannoproteins, and it is also required for extracellular matrix generation by animal cells. Herein, we provide evidence for a uridine diphospho (UDP)-GlcNAc pathway in Pneumocystis species. Using an in silico search of the Pneumocystis jirovecii and P. murina (Pm) genomic databases, we determined the presence of at least four proteins implicated in the Saccharomyces cerevisiae UDP-GlcNAc biosynthetic pathway. These genes, termed GFA1, GNA1, AGM1, and UDP-GlcNAc pyrophosphorylase (UAP1), were either confirmed to be present in the Pneumocystis genomes by PCR, or, in the case of Pm uap1 (Pmuap1), functionally confirmed by direct enzymatic activity assay. Expression analysis using quantitative PCR of Pneumocystis pneumonia in mice demonstrated abundant expression of the Pm uap1 transcript. A GlcNAc-binding recombinant protein and a novel GlcNAc-binding immune detection method both verified the presence of GlcNAc in P. carinii (Pc) lysates. Studies of Pc cell wall fractions using highperformance gas chromatography/mass spectrometry documented the
\end{abstract}

presence of GlcNAc glycosyl residues. Pc was shown to synthesize GlcNAc in vitro. The competitive UDP-GlcNAc substrate synthetic inhibitor, nikkomycin Z, suppressed incorporation of GlcNAc by Pc preparations. Finally, treatment of rats with Pneumocystis pneumonia using nikkomycin $\mathrm{Z}$ significantly reduced organism burdens. Taken together, these data support an important role for GlcNAc generation in the cell surface of Pneumocystis organisms.

Keywords: Pneumocystis; $\mathrm{N}$-acetylglucosamine; nikkomycin Z; cell wall; pathogenesis

\section{Clinical Relevance}

Pneumocystis pneumonia remains an important infection in immune-compromised patients. These studies describe the pathways used to synthesize a specialized sugar, termed $\mathrm{N}$-acetylglucosamine (GlcNAc), which is an important component of the organisms' cell surface. Inhibition of synthesis of GlcNAc reduces organism burden during infection in rodent models.
The amino sugar, $\mathrm{N}$-acetylglucosamine (GlcNAc), is an abundant component of the eukaryotic and prokaryotic cell wall. In yeast, uridine diphospho (UDP)-GlcNAc, the active form of the amino sugar, is an essential precursor needed for the synthesis of glycosylphosphatidylinositol (GPI) anchors, mannoproteins, chitin, and chitosan (1). Members of the UDP-GlcNAc synthetic pathway in fungi have been shown to be essential in fungal growth, and therefore represent viable targets for antifungal therapy. For example, recently, analysis of the Aspergillus fumigatus UDPGlcNAc pyrophosphorylase (UAP), the

(Received in original form May 14, 2016; accepted in final form September 2, 2016)

This work was supported by the Mayo Foundation for Education and Research, the Walter and Leonore Annenberg Foundation, and National Institutes of Health grant R01-HL62150 (A.H.L.), and by the Chemical Sciences, Geosciences, and Biosciences Division, Office of Basic Energy Sciences.

Author Contributions: Conception and design-T.J.K. and A.H.L.; analysis and interpretation-T.J.K., D.M.H., P.E.J., J.H.R.-P., and A.H.L.; drafting the manuscript for important intellectual content-T.J.K., D.M.H., P.E.J., J.H.R.-P., and A.H.L.

Correspondence and requests for reprints should be addressed to Andrew H. Limper, M.D., 8-24 Stabile, Mayo Clinic, Rochester, MN 55905;

E-mail: limper.andrew@mayo.edu

This article has an online supplement, which is accessible from this issue's table of contents at www.atsjournals.org

Am J Respir Cell Mol Biol Vol 56, Iss 2, pp 213-222, Feb 2017

Copyright $\odot 2017$ by the American Thoracic Society

Originally Published in Press as DOI: 10.1165/rcmb.2016-01550C on September 15, 2016

Internet address: www.atsjournals.org 
final enzyme in eukaryotic UDP-GlcNAc biosynthesis, which converts uridine triphosphate and GlcNAc-1-phosphate (GlcNAc-1P) to UDP-GlcNAc, was shown by crystal structure analysis to have enough variation in its composition from the human enzyme to be a potential target for antifungal therapy (2).

The cell surface of the pathogenic fungal species represented by Pneumocystis organisms have not been fully elucidated, but are known to contain $\beta-1,3$ and $\beta-1,6$ glucans, and the major surface mannoserich glycoproteins, variously termed major surface glycoprotein (MSG) or glycoprotein A (gpA) (3-5). We and others have shown that the Pneumocystis species contain $\beta$-glucan synthetases that can be inhibited by specific $\beta$-glucan inhibitors, such as the echinocandins, pneumocandins, and newly generated compounds $(3,4,6,7)$. A number of these drugs are already implemented as antifungal therapies against pathogens (8). Similarly to $\beta$-glucans, mannoproteins on the surface of fungi have been demonstrated to be required for organism viability and to avoid host immune surveillance (9).

Although a number of studies have evaluated the presence and antigenic variation of MSG/gpA, the Pneumocystis equivalent to yeast mannoproteins $(10,11)$, information regarding the initial characterization of the UDP-GlcNAc pathway that most likely provides the chitobiose structure responsible for tethering the membrane-bound mannoprotein to the cell wall is lacking. Herein, we analyze biochemical and genetic evidence and demonstrate the presence of the GlcNAc biosynthesis pathway, as well as GlcNAc-containing molecules on the cell surface of Pneumocystis species.

Identification of GlcNAc-containing residues such as those present in chitobiose or GPI anchored molecules in Pneumocystis species, and their role in cell wall biology, have not been fully studied. For example, over the past 20 years, only a handful of studies have searched for GlcNAc residues in Pneumocystis organisms. These included classic biochemical methods for determination of this moiety in the organism via GlcNAc-binding/-labeling experiments using antibody staining techniques, as well as incorporation of ${ }^{3} \mathrm{H}$-glucosamine into the $P$. carinii $(\mathrm{Pc})$ cell walls, supportive of GlcNAc deposition (12-14). More recently, an intriguing study by Rapaka and colleagues (15) suggested that mice infected with $P$. murina (Pm) could generate increased levels of IgM antibodies against fungal carbohydrates, including GlcNAc-containing carbohydrates. Recently, however, it has been shown that, although Pneumocystis species contain chitin chaperone proteins implicated in proper transportation of major chitin synthases to the cell membrane in yeast, the genomes of Pneumocystis species lack major chitin synthase or chitin-degrading chitinase enzymes (5). In this light, we initiated a comprehensive analysis of the various enzymes potentially leading to the synthesis of GlcNAc in Pneumocystis organisms. Using both detailed biochemical and genetic analytical strategies, we provide evidence that Pneumocystis species indeed possess GlcNAc residues. We further provide cumulative genetic information for a potential GlcNAc biosynthetic pathway in these organisms, serving as an essential precursor of important cell wall components, such as GPI anchors for Pneumocystis MSG/gpA. In addition, treatment of isolated Pc cell wall preparations and rats with Pneumocystis pneumonia (PCP) using nikkomycin Z, an analog of UDP-GlcNAc that acts as a competitive inhibitor of cell surface carbohydrate synthesis, verified significant inhibition of newly synthesized GlcNAc residues in vitro, as well as reduction in Pc organism burdens during infection.

\section{Materials and Methods}

\section{Strains and Reagents}

For these studies, Pc and Pm organisms were originally derived from American Type Culture Collection (Manassas, VA) stocks and propagated in corticosteroid-treated rats or mice, as reported previously $(16,17)$. Populations of Pc were isolated from chronically infected rat lungs by homogenization and filtration through $10-\mu \mathrm{m}$ filters, as we previously described $(3,18)$. Unless otherwise noted, the remaining reagents were obtained from Sigma-Aldrich (St. Louis, MO).

\section{Detailed Experimental Procedures}

Detailed experimental procedures are found in the online supplement. Procedures in the supplement include: immunofluorescence detection of GlcNAc reactivity in Pc (19-26), Western analysis of Pc GlcNAc complexed to proteins $(27,28)$; verification of GlcNAc biosynthetic genes in the Pc and Pneumocystis jirovecii (Pj) genomes (16); expression of Pmuap1 mRNA in Pm-infected mice (29); expression, purification, and enzymatic activity of PmUap1 (2, 16, 30-32); determination of Pc synthesis of GlcNAc (33-35); glycosyl composition of Pc GlcNAc preparations using gas chromatography/mass spectrometry (GC/MS) (36-39); and nikkomycin $\mathrm{Z}$ treatment of Pc-infected rats (40-42). Furthermore, all nucleotide sequence accession numbers are included in the supplement. Specific PCR primers used in these studies are listed in Table E1 in the online supplement.

\section{Statistical Analysis}

Statistical analyses between various experimental conditions were first assessed using ANOVA and subsequently Student's $t$ tests, as indicated. Nonparametric statistics were used when data were distributed in a non-gaussian manner. Statistical testing was performed employing GraphPad Prism version 5.0b (GraphPad Software, Inc., La Jolla, CA), and statistical differences were considered to be significant with a $P$ value of less than 0.05 .

\section{Results}

\section{The Pc Cell Wall Exhibits GIcNAc Reactivity by Immunofluorescence and GIcNAc Binding Analysis}

As an initial characterization of the presence of GlcNAc residues in $\mathrm{Pc}$, we assessed the presence of such molecules in freshly isolated Pc organisms using immunofluorescence (Figure 1). Pc strongly bound wheat-germ agglutinin (WGA), a lectin probe with reactivity to GlcNAccontaining structures (Figure 1C). Similar findings have been previously observed by other investigators $(43,44)$. Because WGA binds not only GlcNAc present in fungal cell wall membranes, but also $\mathrm{N}$-acetylneuraminic acid, the major sialic acid present in mammalian cells, we further used an immunofluorescence assay employing a GlcNAc-recognizing chitin-binding domain (CBD) protein linked to the engineered O-6 methylquanine-DNA methyl transferase (SNAP)-tagged protein $(45,46)$. This proteintagged probe exhibits high specificity for GlcNAc residues, including chitobiose 
(GlcNAc) $)_{2}$, based on its selective binding domain isolated from the bacteria, Bacillus circulans WL-12 (47). After 15 minutes of zymolyase digestion, the SNAP-tagged CBD probe displayed strong binding to $\mathrm{Pc}$

(Figure 1D). Of note, however, some, though not all, Pc organisms in the preparations were detected using this approach. Thus, expression levels of GlcNAc residues may occur at specific times in the organism life cycle or under selected conditions (for example, when production of MSG/gpA mannoproteins are needed for host cell attachment or host evasion by antigenic variation). Taken together, these findings support the presence of GlcNAc residues in Pc.

We next used the SNAP-tagged CBD for Western analysis adapting a method used for detection of $\beta-1,6$ glucans associated with Candida albicans proteins (27). Using this strategy, a prominent GlcNAc-containing protein conjugate band with a size of roughly $45 \mathrm{kD}$ was detected (Figure 2A, left panel). Immune blotting with a nonimmune isotype control antibody yielded no specific reactivity (Figure 2A, right panel).

It has been shown that Streptomyces fungal species exert antifungal activities against pathogenic fungi (48). In Streptomyces griseus, this antifungal activity has been attributed to a major endochitinase, a member of a family of chitinases containing 19 such hydrolytic enzymes, first discovered in plants $(28,49)$. This enzyme cannot only digest chitin polymers, but can also digest chitobiose that is linked to mannoproteins (26). It is of interest that digestion of our Pc cell wall preparations with this endochitinase, followed by PAGE and probing with the SNAP-tagged CBD, resulted in almost complete elimination of the $45-\mathrm{kD}$ band with the formation of a single band of less than $15-\mathrm{kD}$ (Figure 2B). These observations further support the presence of GlcNAccontaining molecules on the Pc cell surface.

\section{The Pj Genomes Contain GIcNAc Biosynthetic Genes}

In Saccharomyces cerevisiae, the GlcNAc metabolism genes, GFA1, GNA1,

PCM1/AGM1, and QRI1/UAP1 are essential for viability (see Figure 3 for the yeast UDP-GlcNAc biosynthetic pathway) (50). In an attempt to determine whether members of these GlcNAc pathway-related genes are present in human-derived $\mathrm{Pj}$, we searched the completed $\mathrm{Pj}$ genome
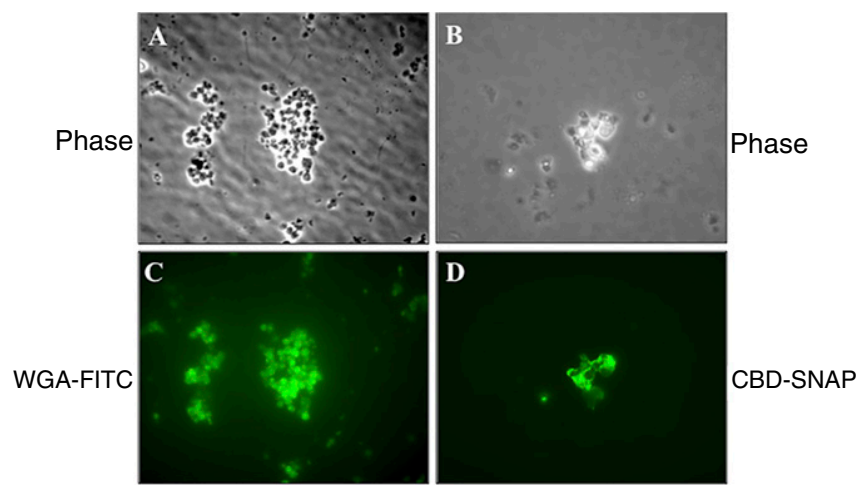

Figure 1. Lectin and affinity binding assays demonstrate $N$-acetylglucosamine (GlcNAc) reactivity in the Pneumocystis cell wall. ( $A$ and $B$ ) Phase microscopy images of Pneumocystis carinii $(\mathrm{PC})$ life forms (200x magnification). (C) Wheat-germ agglutinin (WGA)-FITC staining of Pc life forms. (D) Fluorescence microscopy staining of engineered O-6 methylquanine-DNA methyl transferase (SNAP)tagged chitin-binding domain (CBD) binding protein of Pc life forms followed by addition of polyclona anti-SNAP antibody displays specific staining of Pc organisms. (http://genome.jgi.doe.gov/pnejil/pnejil. home.html) using keywords for these yeast genes. After computer-based analysis of the $\mathrm{Pj}$ genome, we further determined that, indeed, $\mathrm{Pj}$ genomic material from human bronchoalveolar lavage fluid samples contains all four members of the GlcNAc synthetic pathway. In addition, $\mathrm{Pj}$ homologs of the upstream metabolic protein members, Pgilp, a glycolytic phosphoglucose isomerase catalyzing the interconversion of glucose-6-phosphate and fructose-6-phosphate (51), and Hxh2p, glucose in the yeast cell (52), were also detected (Table E2). Primers were designed which catalyzes the phosphorylation of

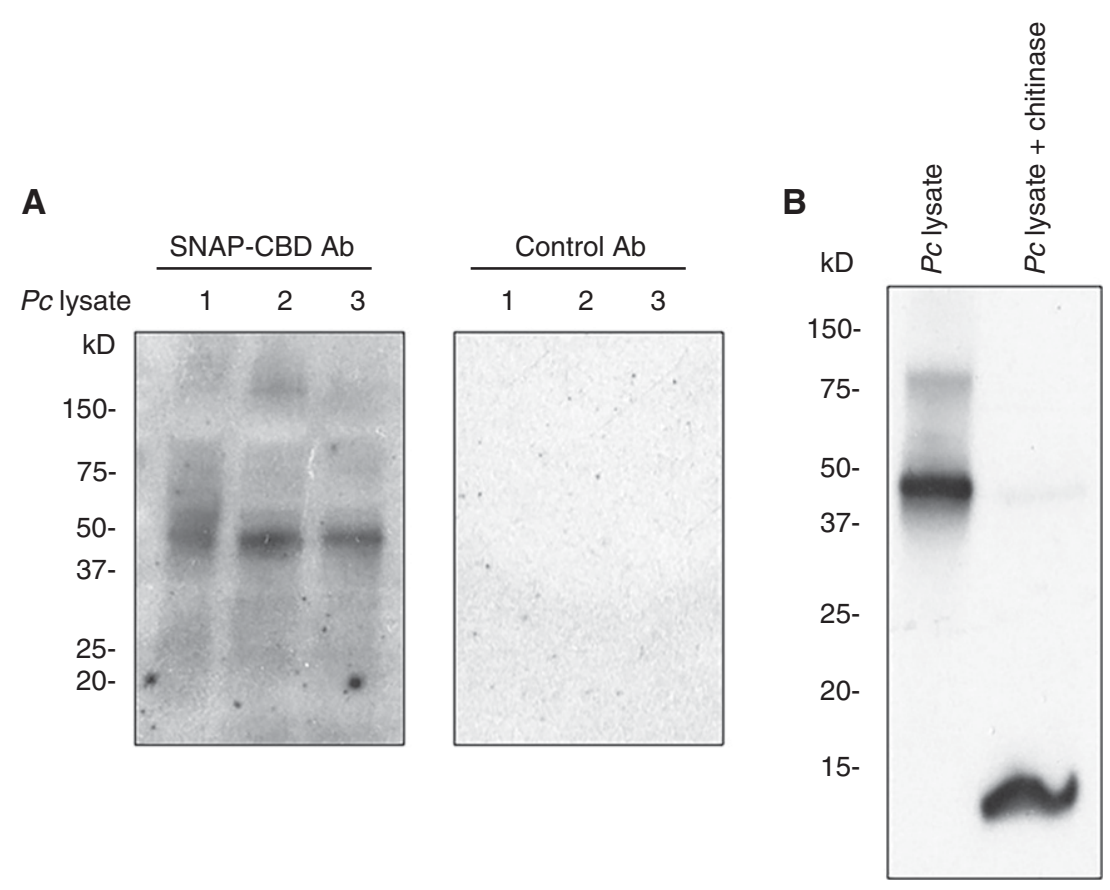

Figure 2. Western analysis of Pc GlcNAc-bound complexes confirms GlcNAc reactivity in Pneumocystis extracts. (A) Pc cell wall preparations were separated by PAGE, and potential GlcNAc complexed to Pc proteins were assayed by SNAP-tagged CBD protein incubation followed by anti-SNAP antibody (Ab) detection. Concentrations of total Pc protein preparations were as follows: lane 1, $100 \mu \mathrm{g}$; lane 2, $50 \mu \mathrm{g}$; lane 3, $25 \mu \mathrm{g}$. (B) Total Pc lysate preparations were either treated with chitinase reaction buffer alone or with $1 \mathrm{U}$ of chitinase from Streptomyces griseus for 2 hours at $37^{\circ} \mathrm{C}$ before analysis. 


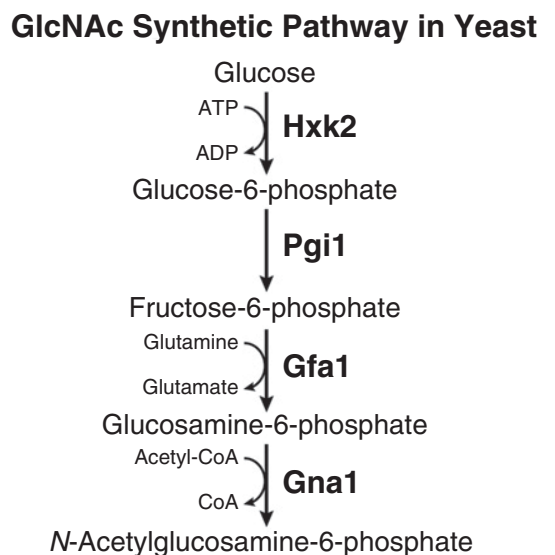

$N$-Acetylglucosamine-6-phosphate

\section{Pcm1/Agm1}

$\mathrm{N}$-Acetylglucosamine-1-phosphate

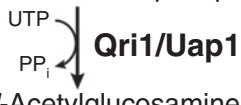

UDP-N-Acetylglucosamine

Figure 3. Uridine diphospho (UDP)-GlcNAc synthetic pathway in Saccharomyces cerevisiae and other yeast. Proteins in bold indicate these genes are confirmed to be present in $P$. jirovecil (Pj). Of note, GFA1, GNA1, PCM1/AGM1, and QR/1/UDP-GlcNAc pyrophosphorylase (UAP1) are essential in $S$. cerevisiae.

based on the cDNA sequences of Pjgfal, Pjgna1, and Pjagm1 (http://genome.jgi.doe. gov/pneji1/pneji1.home.html). These primers were added to either $\mathrm{Pj}$ genomic DNA or healthy human lung genomic DNA. To confirm the Pj Basic Local Alignment Search Tool X (BLASTX) database search, we performed PCR amplification of these three essential GlcNAc-regulatory genes using Pj DNA, and successfully amplified portions of all three GlcNAc synthase pathway genes (Figure 4). A primer set based on $h G A P D H$ confirmed the integrity of the human DNA integrity. Furthermore, because the essential UAP, the final enzyme in the fungal UDP-GlcNAc synthetic pathway, has shown to be a potential antifungal target in A. fumigatus, we also wanted to determine whether the UAP Pj homologue, Pjuap1, was also present in the $\mathrm{Pj}$ material isolated from patients with PCP. Indeed, as shown in Figure $5 \mathrm{~A}$, a specific amplicon was noted, indicating the presence of the UAP homolog within the Pj genomic material. These results provide further evidence for the GlcNAc synthase pathway existing in Pneumocystis species, and of particular importance in $\mathrm{Pj}$, which is responsible for disease in humans.
The Pm Pmuap1 Transcript Is Actively Expressed during PCP in Mice

To confirm whether the final GlcNAc biosynthetic gene Pmuap1 was not only present in the genomes of Pneumocystis species, but also expressed during active infection during PCP, we isolated total RNA from 10-week-old mice with active Pm infection, or healthy, uninfected mouse lungs. After isolation of total RNA and elimination of any potential contaminating genomic DNA, we analyzed the derived RT-amplified cDNA for the presence of actively transcribed mRNA for the GlcNAc biosynthetic gene. We observed abundant mRNA transcription by quantitative PCR (qPCR) of Pmuap1. No amplification occurred using the mRNA samples from healthy mouse control lungs (Figure $5 \mathrm{~B}$ ). These data indicate that, during PCP, the organisms actively transcribe Pmuap1 mRNA.

\section{Pneumocystis Possesses a Functional Uap1p Enzyme}

To further determine whether Pneumocystis species contain a functional Uap1p enzyme, essential for the yeast metabolic GlcNAc synthase pathway, the Pm-derived Pmuap1 cDNA was cloned into a bacterial vector for expressing fusion proteins with a thrombin cleavage site and expressed with a glutathione $S$-transferase (GST) fusion tag in Escherichia coli. After purification with glutathione sepharose, PmUaplp activity and substrate preference was assessed by incubation of the enzyme with uridine triphosphate and either the phosphosugar, GlcNAc-1P (the preferred substrate before GlcNAc in the GlcNAc synthetic pathway) $(2,32)$ or with glucose-1-phosphate (Glc-1P) a nonpreferred substrate for Uaplp in yeast (32). As demonstrated in Figure 5C, PmUaplp exhibits preference for GlcNAc$1 \mathrm{P}$, although it can also cleave phosphate from the Glc-1P substrate, but to a much lesser degree than GlcNAc-1P. Figure E1 further demonstrates that, when another nonspecific substrate, mannose 1-phosphate, was used and incubated with PmUaplp, only negligible amounts of detectable free pyrophosphate were generated (see the online supplement). Cleavage of phosphate to inorganic pyrophosphate has also been previously demonstrated in S. cerevisiae with Uap1p acting on Glc-1P, which has been termed "dual substrate utility" (32). Thus, our results indicate that PmUap1 can function as a UAP similar to Uap1 proteins in the GlcNAc biosynthetic pathway of other fungi.

\section{GIcNAc Incorporation into the Pc Cell Wall}

We further measured the incorporation of UDP-N-GlcNAc into insoluble cell surface products in Pc. Total Pc cell preparations were incubated in reaction buffer as previously described at various temperatures and de novo UDP-GlcNAc incorporation into insoluble GlcNAc cell surface material detected using wheat germ

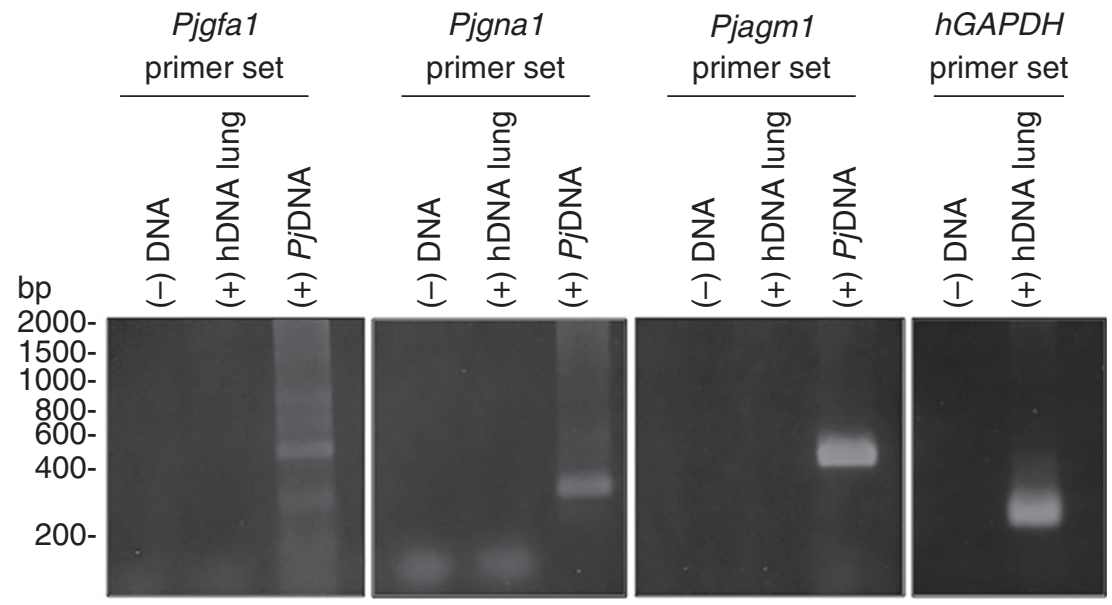

Figure 4. $\mathrm{Pj}$ GlcNAc biosynthetic pathway homolog genes are present in organisms derived from human bronchoalveolar lavage fluid (BALF). Pjgfa1-, Pjgna1-, and Pjagm1-specific primer sets amplified specific products from Pj genomic DNA derived from BALF but not human genomic DNA. Human glyceraldehyde-3-phosphate dehydrogenase ( $h G A P D H)$ serves as an appropriate amplification control. bp, base pairs. 
A

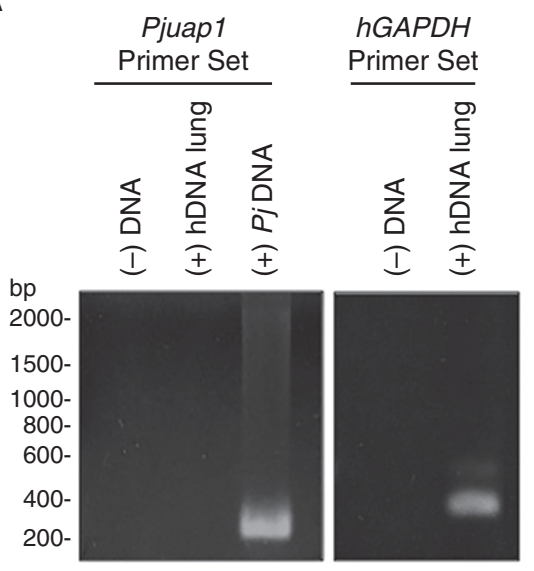

B

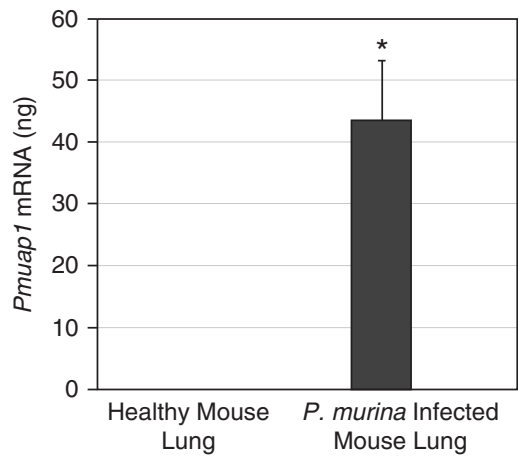

C

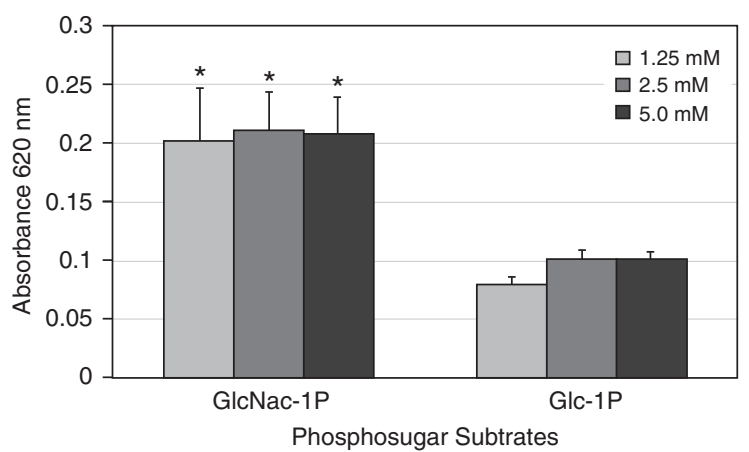

Figure 5. Pneumocystis species genomes contain a functional Uap1 final biosynthetic enzyme in the GlcNAc pathway, and this transcript is abundantly expressed in mice with Pneumocystis pneumonia (PCP). (A) Amplification of Pjuap1 from Pj genomic DNA confirms its presence in this genome.

(B) Active expression of $P$. murina (Pm) uap1 (Pmuap1) during PCP in the mouse model suggests abundant expression of this GlcNAc synthesis gene during Pneumocystis infection $\left({ }^{\star} P<0.01\right.$ comparing expression in Pm-infected lung samples to uninfected healthy lung). (C) PmUap1 protein incorporation assay confirms enzymatic activity. Specificity of phosphosugar substrates for utilization by PmUap1p was assayed with varying concentrations of uridine triphosphate for 20 minutes at room temperature. Final synthesized products were analyzed by the Biomol green assay coupled with yeast pyrophosphatase. The results are expressed as the mean $( \pm \mathrm{SD})$ for three experimental determinations ( ${ }^{\star} P<0.01$ comparing GlcNAc-1-phosphate [GlcNac-1P] to glucose-1-phosphate (Glc-1P) activity in the assay at identical concentrations).

agglutinin (WGA)-horse radish peroxidase (HRP) conjugate $(33,53)$. Because Pneumocystis spp. are mammalian lung pathogens, the organism's preferred temperature of growth in vivo is approximately $37^{\circ} \mathrm{C}$, conditions that have been confirmed in the laboratory for shortterm maintenance of the organisms in vitro $(54,55)$. Therefore, as expected, newly generated GlcNAc, as measured by GlcNAc incorporation into insoluble cell surface products, was observed to increase as the reaction temperatures increased from room temperature $\left(26^{\circ} \mathrm{C}\right)$ to $37^{\circ} \mathrm{C}$ (Figure $6 \mathrm{~A}$ ). These experiments document optimal incorporation of GlcNAc into the Pc cell wall under conditions relevant to infection in the mammalian host.

To further confirm our potential findings that Pc has the ability to incorporate GlcNAc into Pc cell surface components, we added the competitive UDP-GlcNAc analog, nikkomycin Z, to our enzymatic assays. In other fungi, nikkomycin $\mathrm{Z}$ typically suppresses the synthesis of chitin and other GlcNAccontaining cell surface components through competitive inhibition of GlcNAc incorporation (56). Recently, nikkomycin Z has also been demonstrated to have activity against the bacterial, a $\beta-1,4-N$ acetylglucosamine transferase (57). Even though Pneumocystis genomic analyses recently suggested the absence of chitin synthetic and degradative genes in Pneumocystis species, our data strongly support the present of other GlcNAccontaining molecules on the Pc cell surface. Accordingly, we tested the effects of nikkomycin $\mathrm{Z}$ on $\mathrm{Pc}$ incorporation of GlcNAc molecules by the organisms. Incubation with nikkomycin $\mathrm{Z}$ significantly reduced the generation of newly synthesized GlcNAc containing precipitable material by Pc preparations, as measured by the WGA-HRP binding assay (Figure 6B). Our results indicate that Pneumocystis species have the ability to incorporate GlcNAc into cell surface components, and that nikkomycin $\mathrm{Z}$ can inhibit this activity.

\section{Determination of Glycosyl Residue Composition of Pc Cell Preparations by GC-MS}

Biochemical support for the existence of GlcNAc in Pneumocystis species further required the isolation of the material from the organism. For this process, we implemented an extraction protocol as described by Wagener and colleagues (58). After extraction of the Pc cell surface material, the resulting samples were analyzed by GC-MS methods, as previously described (59). The results of the analysis are shown in Table E3. Of the total mole percent of the glycosyl residues analyzed, roughly $20 \%$ of the sample had GlcNAc. These results further support that Pneumocystis species possess GlcNAc containing material within their insoluble cell surface components.

\section{Efficacy of the Inhibitor, Nikkomycin $Z$, in the Rat Model of PCP}

Finally, we evaluated the use of nikkomycin $\mathrm{Z}$, a competitive antagonist of GlcNAc incorporation, for treatment of active PCP. To accomplish this, we employed the rat Pc pneumonia model that has been used extensively to analyze drug activity against the organism $(6,60,61)$. Due to limited drug supply, we treated the rats with nikkomycin $\mathrm{Z}$ by oral gavage after establishment of fulminate PCP by immune suppressing rats with corticosteroids and inoculating with Pc. The animals were maintained on the immune suppressive regimen for 8 weeks to develop active PCP. 
A

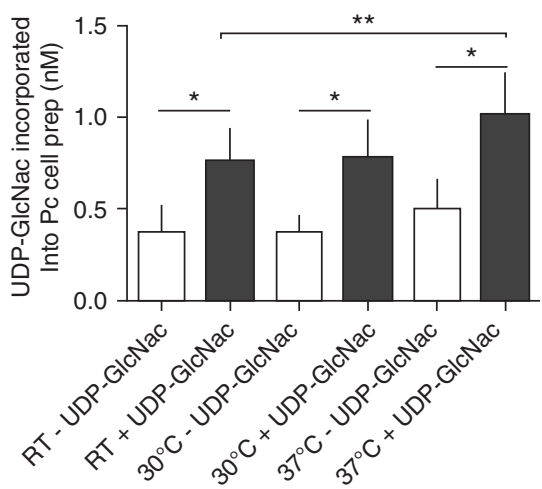

B

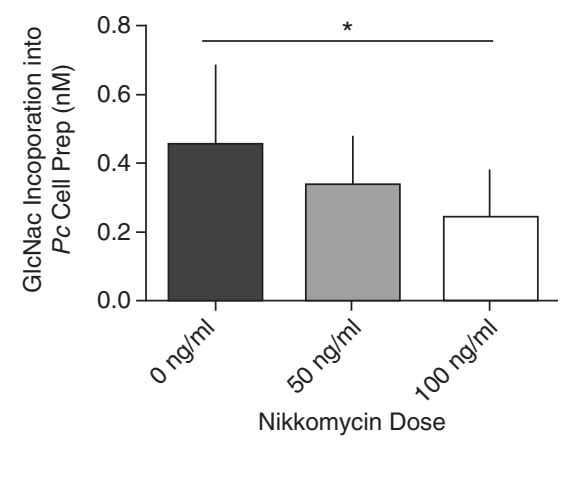

Figure 6. GlcNAc is incorporated into Pc cell preparations and is inhibited by nikkomycin Z. (A) De novo incorporation of GlcNAc into Pc cell preparations was assessed in the presence of added UDP-GIcNAc (+UDP-GIcNAc) compared with basal incorporation of GlcNAc by the Pc cell preps $(-$ UDP-GlcNAc). Shown are the mean $( \pm S D)$ from three determinations performed in triplicate $\left({ }^{\star} P<0.05\right.$, significant GlcNAc incorporation at each temperature condition compared with the baseline levels of GlcNAc measured in reactions without added UDP-GlcNAc, ${ }^{\star \star} P<0.05$ comparing UDP-GlcNAc incorporation at $37^{\circ} \mathrm{C}$ to room temperature [RT]). (B) Nikkomycin Z inhibits GlcNAc incorporation into the Pc cell preparations. GlcNAc incorporation by Pc cell preparations was measured in the presence of UDP-GlcNAc and increasing concentrations of nikkomycin at $37^{\circ} \mathrm{C}$ $\left({ }^{\star} P<0.01\right.$, significant suppression of GlcNAc incorporation).

Thereafter, we provided twice-daily nikkomycin $\mathrm{Z}$ by oral gavage for 7 days. This regimen was selected due to the relatively short half-life of this drug and the success of this method in treating experimental pulmonary blastomycosis (62). After treatment with nikkomycin Z, rat lungs were harvested and RNA isolated from the lungs. Pc organism burden was determined by qPCR. Similar to what has been shown for other fungal pathogens $(62,63)$, we observed significant reductions in Pc organism burden in the infected lungs of the rats treated with nikkomycin $\mathrm{Z}$ compared with the saline control group (Figure 7E). Furthermore, histology of rodent lungs from animals treated with nikkomycin $\mathrm{Z}$ demonstrated greatly reduced organism burdens, as visualized by hematoxylin and eosin and Gomori methenamine silver staining (Figures 7A-7D), respectively.

We further used a novel qPCR technique to analyze Pc life form-associated mRNAs to determine whether nikkomycin $\mathrm{Z}$ affects both the trophic and cyst forms of the organism. To accomplish this, we used qPCR quantitation of Pcint1 RNA, a gene expressed predominantly by trophic forms (42), and Pcran 1 RNA, a gene expressed largely by the cyst forms of the organisms (41) (Figure E2). Using this approach, we observed that nikkomycin $\mathrm{Z}$ treatment of $P c$-infected rats significantly reduced both forms of the organism, with observed reduction of the Pcint1 RNA associated with trophic forms by $94.1( \pm 2.7) \%(P=$ 0.0004), and reduction of the Pcran 1 RNA associated with cyst forms by $85.3( \pm 3.9) \%$ $(P=0013)$. Due to the reported absence of chitin synthetic genes from the Pneumocystis species genome (5), these results suggest that nikkomycin $\mathrm{Z}$ can also potentially inhibit incorporation of GlcNAc into other cellular components, thereby impairing viability of the organisms. As such, these results support extended activity for nikkomycin $\mathrm{Z}$ as a potential agent in the treatment of PCP affecting both life cycle forms of the organism.

\section{Discussion}

$\mathrm{Pj}$ causes life-threatening pneumonia in immunocompromised patients, with an estimated 400,000 cases of PCP occurring annually worldwide and resulting mortalities as high as $80 \%$ in certain patient groups (64). PCP is considered the second most important invasive fungal infection in the world, only behind Cryptococcosis, and having far greater numbers than Aspergillosis and Histoplasmosis combined (64). With these concerns, additional research is required to understand the organism's life cycle and to develop new agents for therapy. One area for potential therapeutic exploitation is the cell surface of Pneumocystis. For instance, targeting the Pneumocystis $\beta-1,3$ and $\beta-1,6$ glucan synthases, which generate major structural carbohydrates on the cell surface, may represent a novel therapeutic approach for this infection $(3,4,7,61,65)$. Unfortunately, a comprehensive understanding of the Pneumocystis cell surface has not yet been elucidated. A recent keyword search of PubMed for "yeast cell wall" yielded over 7,000 publications compared with only 115 for "Pneumocystis cell wall." In addition to $\beta$-glucans, most fungi also contain cell wall mannoproteins (mannans), which are important cell wall polysaccharides, typically containing an $\alpha-(1-6)-$ linked backbone and $\alpha(1,2)$ and $\alpha(1-3)$-linked branch chains (66). Some fungi, such as $C$. albicans, have more elaborate and extensive side-chain branching (67). In pathogenic fungi, mannans have been shown to be important for host cell binding, inhibition of macrophage cell uptake, and for masking inflammatory $\beta$-glucans (9). GlcNAc is essential for fungi to synthesize mannan structures and to properly localize $\beta$-glucans in the cell wall.

Fungal mannoprotein attachment to the cell membrane generally requires the presence of the chitobiose ( $\mathrm{GlcNAc})_{2}$ core (68). However, in some fungi, such as $C$. albicans, genomic analyses suggest that there are over 100 putative GPIanchored proteins, twice that of $S$. cerevisiae (69). These GPI-anchored proteins are linked at the carboxyl terminus through a phosphodiester linkage of phosphoethanolamine to a trimannosylnonacetylated glucosamine core (70). Mutations in these GPI-anchored proteins in yeast lead to profound growth defects, loss of cell wall integrity, increased sensitivity to antifungal agents, and reduction in virulence $(69,71)$. In Pneumocystis species, the presence of GPIlinked cell wall proteins is also important to the life cycle of the organism. For example, the MSG/gpA superfamily of Pneumocystis mannoproteins is bound to the cell surface by a GlcNAc-containing chitobiose core. It is noteworthy that MSG/gpA represents an astounding 3-6\% of the genomes of Pneumocystis species (5), further suggesting the importance of these mannoproteins in the organism's life cycle. We have also shown that Pc contains an additional GPIanchored protein, termed PcPhrlp, a 
A

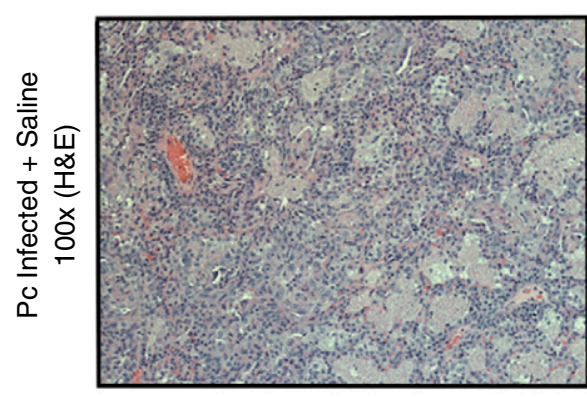

B

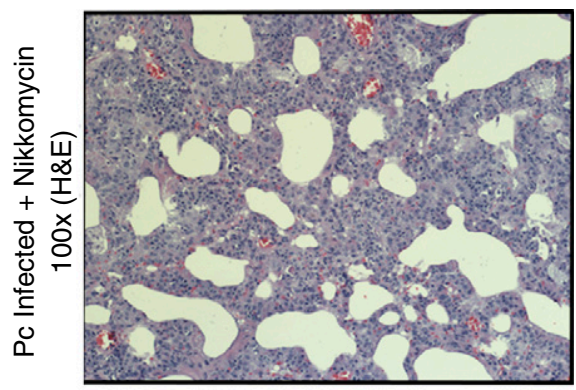

C

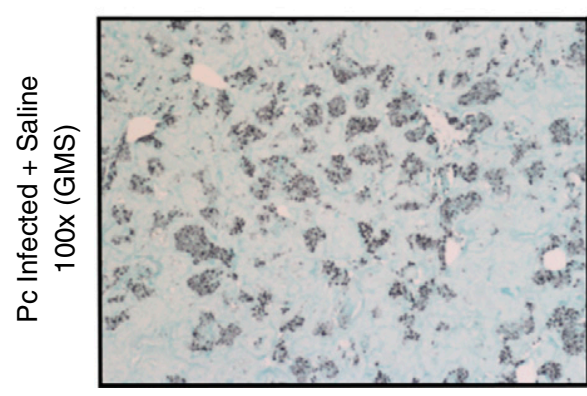

D

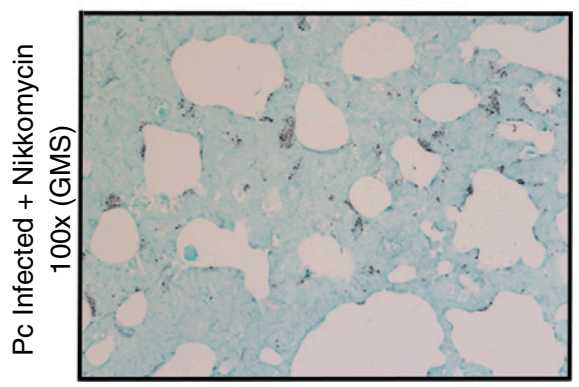

$\mathbf{E}$

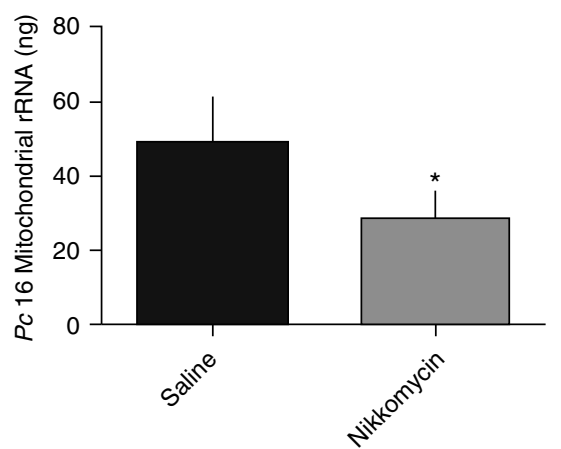

Figure 7. Nikkomycin Z reduces Pc organism burden during PCP. After the establishment of fulminate PCP in rats, nikkomycin $Z$ treatment $(20 \mathrm{mg} / \mathrm{kg})$ was administered twice daily for 7 days. After this therapy, the rats were killed and histology and Pc organism burden determined, as described in the MateRIALS AND Methods. A total of six rats per treatment group was analyzed. (A) Pneumocystis-infected rats treated with saline, hematoxylin and eosin (H\&E) staining; $(B)$ Pneumocystis-infected rats treated with nikkomycin Z, H\&E staining; (C) Pneumocystis-infected rats treated with saline, Gomori methenamine silver (GMS) staining; and (D) Pneumocystis-infected rats treated with nikkomycin Z, and stained with GMS. All images were photographed at $\times 100$ magnification. $(E)$ The Pc organism burdens were further determined by quantifying 165 mitochondrial RNA, which further documented significant reduction of Pc organism burdens in the rats with PCP treated with nikkomycin $Z$ ( ${ }^{\star} P<0.05$, comparing nikkomycin treatment to saline-treated controls with $\left.P C P\right)$.

putative glycosidase required for proper cross-linking of $\beta-1,3$ and $\beta$-1,6-glucans that provides structural integrity to the Pneumocystis cell wall (72). Deletions in these carbohydrate cross-linking proteins have profound morphological and virulence defects in other fungi $(73,74)$. Taken together, these observations indicate that inhibiting GlcNAc biosynthetic pathways might provide a novel strategy for PCP therapy.

With this background in mind, we sought to evaluate the available evidence supporting the presence of a functional UDP-GlcNAc pathway in Pneumocystis species. As an initial step to determine the potential presence of GlcNAc, immunofluorescence microscopy studies were performed with WGA-FITC, a fluorescent reagent that binds terminal GlcNAc, chitobiose, and chitooligosaccharides. In addition, we used a recombinant $\mathrm{CBD}$ protein known to bind chitobiose and chito-oligosaccharides. Both approaches demonstrated significant binding to Pc, supporting the presence of GlcNAc-containing molecules in the cell wall of Pneumocystis organisms.

We further searched for the presence of GlcNAc biosynthetic-related genes in genomes of Pneumocystis species. With the advent of the newly completed $\mathrm{Pc}, \mathrm{Pj}$, and $\mathrm{Pm}$ databases (5), we performed a comprehensive search for other genes related to GlcNAc biosynthesis (Figure 3). Our in silico search verified the presence of a number of new GlcNAc synthase pathway genes in these Pneumocystis species. These include sequences for GFA1, GNA1, AGM1, and UAP1 in the Pj genome, with their presence being verified using PCR on $\mathrm{Pj}$ isolated from the bronchoalveolar lavage fluid of patients suffering from PCP. We were further able to verify the activity of the PmUap1 protein. Uaplp is a fungal UAP required in the last step of GlcNAc biosynthesis to generate the substrate, UDP-GlcNAc, for the major chitin synthases in yeast, and to provide the GlcNAc substrate for GPI linkages for fungal mannoproteins or functional GPIanchored proteins $(32,75)$. PmUap1 protein was expressed in E. coli and used to confirm the appropriate biochemical activity measured by release of inorganic phosphate. Interestingly, PmUaplp could also cleave glucose-1-phosphate (Glc-1P), a phenomenon that has also been observed with Uap1p form S. cerevisiae (32). Of note, Uap1p proteins are essential for viability in some fungi, as evidenced by a recent report that a conditional mutant in A. fumigatus resulted in significant defects in cell survival due to altered cell wall carbohydrate composition and structure. Of further interest, the crystal structure of $A$. fumigatus Uap1p was elucidated and shown to possess substantial differences from the human enzyme (2). These observations, along with the abundant expression profile of Pmuap1 during active PCP in mice, suggest that the $\mathrm{PjU}$ Uap 1 protein may also represent another viable target for PCP therapy.

To confirm the active deposition of GlcNAc into the cell wall, Pc cell wall preparations were analyzed and shown to incorporate GlcNAc into cell wall 
carbohydrate, as measured by WGA-HRP binding (53). Furthermore, this activity was shown to be greatest at $37^{\circ} \mathrm{C}$, the usual temperature present in the lung environment. These results confirm that not only does Pneumocystis contain a complete GlcNAc pathway in its genome, but also that the fungus can use this pathway to generate GlcNAc residues and deposit them in the cell wall. Finally, we demonstrated that treatment of Pc cell wall membrane preparations with nikkomycin Z, an analog of UDP-GlcNAc, significantly reduced GlcNAc incorporation by Pc cell wall preparations.

These observations encourage us to use nikkomycin as a potential therapy in our rat models of PCP. Twice-daily gavage treatment with the agent significantly reduced the organism burden in the rodent PCP model. Interestingly, we observed that nikkomycin $\mathrm{Z}$ reduced both cyst and trophic forms of the organism. Recent evidence suggests that Pneumocystis may not contain an extensive GlcNAc-containing chitin matrix found in many other fungi (5). However, GlcNAc-containing chitobiose dimers are also important core molecules needed for the generation of mannoproteins and mannans (5). We, therefore, postulate that GlcNAc residues are needed to establish the core structures needed for certain Pneumocystis surface glycoconjugates, including potential MSG/gpA complexes. Regardless, our initial proof-of-concept studies provide evidence that nikkomycin $\mathrm{Z}$ may represent a viable treatment for PCP that impacts both forms of the organism. Additional full-dose and time-ranging experiments will be required to determine whether higher doses and longer treatment schedules of nikkomycin $\mathrm{Z}$ may completely eliminate Pneumocystis infections.

Because recent data suggest the absence of synthetic and degradative chitin proteins in Pneumocystis species (5), our data suggest that this antifungal agent might be targeting other Pneumocystis cell surface biosynthetic pathways. Because chitobiose is a core molecule for mannoprotein synthesis, nikkomycin may potentially impact processing and generation of MSG/gpA. In addition, one interesting Pneumocystis gene that we have cloned in the past is termed Pcgcs1 (accession no. AF338415), and functions as a glucosylceramide synthase (Gcs) homolog. Mammalian Gcs proteins are known to also use UDP-GlcNAc as a substrate (76). Gcs proteins typically catalyze the formation of glucosylceramide from ceramide and UDPglucose (76). In pathogenic fungi, such as
Cryptococcus neoformans and Penicillium digitatum, such ceramide conjugates are also required for proper growth and virulence $(77,78)$. Nikkomycin $\mathrm{Z}$ may also inhibit such pathways.

In summary, we have characterized the presence of a UDP-GlcNAc biosynthetic pathway in Pneumocystis species, as well as the presence of GlcNAc in the organism. Furthermore, treatment with nikkomycin $\mathrm{Z}$ inhibited the synthetic ability of cell preparations to incorporate GlcNAc into insoluble cell components, and this agent further significantly decreased the Pc organism burden in the lung during active infection. Due to the overall importance of the UDP-GlcNAc pathway in fungi, this initial characterization of this pathway in Pneumocystis should lead to exploiting these enzymes as potential targets for the treatment of PCP.

\section{Author disclosures are available with the text} of this article at www.atsjournals.org.

Acknowledgments: The authors wish to thank Dr. Paristoo Azadi (Carbohydrate Research Center, University of Georgia, Athens) who performed the carbohydrate analysis on a fee-forservice basis. The Carbohydrate Research Center is also supported by U.S. Department of Energy grant DE-FG02-93ER20097.

\section{References}

1. Milewski S, Gabriel I, Olchowy J. Enzymes of UDP-GlcNAc biosynthesis in yeast. Yeast 2006;23:1-14.

2. Fang W, Du T, Raimi OG, Hurtado-Guerrero R, Urbaniak MD, Ibrahim AF, Ferguson MA, Jin C, van Aalten DM. Genetic and structural validation of Aspergillus fumigatus UDP- $N$-acetylglucosamine pyrophosphorylase as an antifungal target. Mol Microbiol 2013;89:479-493.

3. Kottom TJ, Hebrink DM, Jenson PE, Gudmundsson G, Limper AH. Evidence for pro-inflammatory $\beta-1,6$ glucans in the Pneumocystis cell wall. Infect Immun 2015;83:2816-2826.

4. Kottom TJ, Limper AH. Cell wall assembly by Pneumocystis carinii: evidence for a unique gsc-1 subunit mediating $\beta-1,3$-glucan deposition. J Biol Chem 2000;275:40628-40634.

5. Ma L, Chen Z, Huang W, Kutty G, Ishihara M, Wang H, Abouelleil A, Bishop L, Davey E, Deng R, et al. Genome analysis of three Pneumocystis species reveals adaptation mechanisms to life exclusively in mammalian hosts. Nat Commun 2016;7:10740.

6. Cushion MT, Linke MJ, Ashbaugh A, Sesterhenn T, Collins MS, Lynch K, Brubaker R, Walzer PD. Echinocandin treatment of Pneumocystis pneumonia in rodent models depletes cysts leaving trophic burdens that cannot transmit the infection. PLoS One 2010;5: e8524.

7. Sun $P$, Tong Z. Efficacy of caspofungin, a 1,3- $\beta$-D-glucan synthase inhibitor, on Pneumocystis carinii pneumonia in rats. Med Mycol 2014; 52:798-803.

8. Nett JE, Andes DR. Antifungal agents: spectrum of activity, pharmacology, and clinical indications. Infect Dis Clin North Am 2016;30:51-83.

9. Hall RA, Gow NA. Mannosylation in Candida albicans: role in cell wall function and immune recognition. Mol Microbiol 2013;90:1147-1161.
10. Gigliotti F, Haidaris PJ, Haidaris CG, Wright TW, Van der Meid KR. Further evidence of host species-specific variation in antigens of Pneumocystis carinii using the polymerase chain reaction. $J$ Infect Dis 1993;168:191-194.

11. O'Riordan DM, Standing JE, Limper AH. Pneumocystis carinii glycoprotein A binds macrophage mannose receptors. Infect Immun 1995;63:779-784.

12. De Stefano JA, Cushion MT, Puvanesarajah V, Walzer PD. Analysis of Pneumocystis carinii cyst wall. II. Sugar composition. J Protozool 1990;37:436-441.

13. Garner RE, Walker AN, Horst MN. Morphologic and biochemical studies of chitin expression in Pneumocystis carinii. J Protozool 1991;38:12S-14S.

14. Walker AN, Garner RE, Horst MN. Immunocytochemical detection of chitin in Pneumocystis carinii. Infect Immun 1990;58:412-415.

15. Rapaka RR, Ricks DM, Alcorn JF, Chen K, Khader SA, Zheng M, Plevy S, Bengtén E, Kolls JK. Conserved natural IgM antibodies mediate innate and adaptive immunity against the opportunistic fungus Pneumocystis murina. J Exp Med 2010;207:29072919

16. Dahlin JL, Kottom T, Han J, Zhou H, Walters MA, Zhang Z, Limper AH. Pneumocystis jirovecii Rtt109, a novel drug target for Pneumocystis pneumonia in immunosuppressed humans. Antimicrob Agents Chemother 2014;58:3650-3659.

17. Limper AH, Edens M, Anders RA, Leof EB. Pneumocystis carinii inhibits cyclin-dependent kinase activity in lung epithelial cells. J Clin Invest 1998;101:1148-1155

18. Kottom TJ, Limper AH. Pneumocystis carinii cell wall biosynthesis kinase gene CBK1 is an environmentally responsive gene that complements cell wall defects of $c b k$-deficient yeast. Infect Immun 2004;72:4628-4636. 
19. Kitamura K, Yamamoto Y. Purification and properties of an enzyme, zymolyase, which lyses viable yeast cells. Arch Biochem Biophys 1972;153:403-406.

20. Matsumoto Y, Yamada M, Amagai T. Yeast glucan of Pneumocystis carinii cyst wall: an excellent target for chemotherapy. J Protozool 1991;38:6S-7S.

21. Matsumoto Y, Matsuda S, Tegoshi T. Yeast glucan in the cyst wall of Pneumocystis carinii. J Protozool 1989;36:21S-22S.

22. Van Dyken SJ, Garcia D, Porter P, Huang X, Quinlan PJ, Blanc PD, Corry DB, Locksley RM. Fungal chitin from asthma-associated home environments induces eosinophilic lung infiltration. J Immunol 2011; 187:2261-2267.

23. Watanabe T, Ito Y, Yamada T, Hashimoto M, Sekine S, Tanaka H. The roles of the C-terminal domain and type III domains of chitinase A1 from Bacillus circulans WL-12 in chitin degradation. J Bacteriol 1994; 176:4465-4472.

24. di Guan C, Li P, Riggs PD, Inouye H. Vectors that facilitate the expression and purification of foreign peptides in Escherichia coli by fusion to maltose-binding protein. Gene 1988;67:21-30.

25. Monsigny M, Sene C, Obrenovitch A, Roche AC, Delmotte F, Boschetti E. Properties of succinylated wheat-germ agglutinin. Eur J Biochem 1979;98:39-45.

26. Frederiksen RF, Paspaliari DK, Larsen T, Storgaard BG, Larsen MH, Ingmer $\mathrm{H}$, Palcic MM, Leisner JJ. Bacterial chitinases and chitin-binding proteins as virulence factors. Microbiology 2013;159:833-847.

27. Kitamura A, Someya K, Hata M, Nakajima R, Takemura M. Discovery of a small-molecule inhibitor of $\beta-1,6$-glucan synthesis. Antimicrob Agents Chemother 2009;53:670-677.

28. Rabeeth M, Anitha A, Srikanth G. Purification of an antifungal endochitinase from a potential biocontrol agent Streptomyces griseus. Pak J Biol Sci 2011;14:788-797.

29. Villegas LR, Kottom TJ, Limper AH. Chitinases in Pneumocystis carinii pneumonia. Med Microbiol Immunol (Berl) 2012;201:337-348.

30. Kottom TJ, Han J, Zhang Z, Limper AH. Pneumocystis carinii expresses an active Rtt109 histone acetyltransferase. Am J Respir Cell Mol Biol 2011;44:768-776.

31. Pupaibool J, Kottom TJ, Bouchonville K, Limper AH. Characterization of the Pneumocystis carinii histone acetyltransferase chaperone proteins PcAsf1 and PcVps75. Infect Immun 2013;81:2268-2275.

32. Mio T, Yabe T, Arisawa M, Yamada-Okabe H. The eukaryotic UDP-Nacetylglucosamine pyrophosphorylases: gene cloning, protein expression, and catalytic mechanism. J Biol Chem 1998;273: 14392-14397.

33. Lucero HA, Kuranda MJ, Bulik DA. A nonradioactive, high throughput assay for chitin synthase activity. Anal Biochem 2002;305:97-105.

34. Thomas CF Jr, Limper AH. Current insights into the biology and pathogenesis of Pneumocystis pneumonia. Nat Rev Microbiol 2007; 5:298-308.

35. Engel $\mathrm{P}$, Ullah $\mathrm{AH}$. Mutation affecting peptide bond formation in nikkomycin biosynthesis. Biochem Biophys Res Commun 1988;156: 695-700.

36. Durkin MM, Shaw MM, Bartlett MS, Smith JW. Culture and filtration methods for obtaining Pneumocystis carinii trophozoites and cysts. $J$ Protozool 1991;38:210S-212S.

37. Mora-Montes HM, McKenzie C, Bain JM, Lewis LE, Erwig LP, Gow NA. Interactions between macrophages and cell wall oligosaccharides of Candida albicans. Methods Mol Biol 2012;845:247-260.

38. Merkle RK, Poppe I. Carbohydrate composition analysis of glycoconjugates by gas-liquid chromatography/mass spectrometry. Methods Enzymol 1994;230:1-15.

39. York WS, Darvill M, McNeil TT, Stevenson P, Albersheim P. Isolation and characterization of plant cell walls and cell-wall components. Methods Enzymol 1986;118:3-40.

40. Wakefield AE, Pixley FJ, Banerji S, Sinclair K, Miller RF, Moxon ER, Hopkin JM. Detection of Pneumocystis carinii with DNA amplification. Lancet 1990;336:451-453.

41. Burgess JW, Kottom TJ, Limper AH. Pneumocystis carinii exhibits a conserved meiotic control pathway. Infect Immun 2008;76:417-425.

42. Kottom TJ, Kennedy CC, Limper AH. Pneumocystis PCINT1, a molecule with integrin-like features that mediates organism adhesion to fibronectin. Mol Microbiol 2008;67:747-761.
43. Cushion MT, DeStefano JA, Walzer PD. Pneumocystis carinii: surface reactive carbohydrates detected by lectin probes. Exp Parasitol 1988;67:137-147.

44. Yoshikawa H, Tegoshi T, Yoshida Y. Detection of surface carbohydrates of Pneumocystis carinii. J Protozool 1989;36:63S-64S.

45. Severi E, Hood DW, Thomas GH. Sialic acid utilization by bacterial pathogens. Microbiology 2007;153:2817-2822.

46. Keppler A, Pick H, Arrivoli C, Vogel H, Johnsson K. Labeling of fusion proteins with synthetic fluorophores in live cells. Proc Natl Acad Sci USA 2004;101:9955-9959.

47. Hashimoto M, Ikegami T, Seino S, Ohuchi N, Fukada H, Sugiyama J, Shirakawa M, Watanabe T. Expression and characterization of the chitin-binding domain of chitinase A1 from Bacillus circulans WL-12. J Bacteriol 2000;182:3045-3054.

48. Crawford DL, Lynch JM, Whipps JM, Ousley MA. Isolation and characterization of actinomycete antagonists of a fungal root pathogen. Appl Environ Microbiol 1993;59:3899-3905.

49. Watanabe T, Kanai R, Kawase T, Tanabe T, Mitsutomi M, Sakuda S, Miyashita K. Family 19 chitinases of Streptomyces species: characterization and distribution. Microbiology 1999;145:3353-3363.

50. Wendland J, Schaub Y, Walther A. N-acetylglucosamine utilization by Saccharomyces cerevisiae based on expression of Candida albicans NAG genes. Appl Environ Microbiol 2009;75:5840-5845.

51. Aguilera A, Zimmermann FK. Isolation and molecular analysis of the phosphoglucose isomerase structural gene of Saccharomyces cerevisiae. Mol Gen Genet 1986;202:83-89.

52. Rodríguez A, De La Cera T, Herrero P, Moreno F. The hexokinase 2 protein regulates the expression of the GLK1, HXK1 and HXK2 genes of Saccharomyces cerevisiae. Biochem J 2001;355:625-631.

53. Yarden O, Yanofsky C. Chitin synthase 1 plays a major role in cell wall biogenesis in Neurospora crassa. Genes Dev 1991;5:2420-2430.

54. Cushion MT, Ebbets D. Growth and metabolism of Pneumocystis carinii in axenic culture. J Clin Microbiol 1990;28:1385-1394.

55. Cushion MT, Ruffolo JJ, Linke MJ, Walzer PD. Pneumocystis carinii: growth variables and estimates in the A549 and WI-38 VA13 human cell lines. Exp Parasitol 1985;60:43-54.

56. Sable CA, Strohmaier KM, Chodakewitz JA. Advances in antifungal therapy. Annu Rev Med 2008;59:361-379.

57. Dorfmueller HC, Ferenbach AT, Borodkin VS, van Aalten DM. A structural and biochemical model of processive chitin synthesis. J Biol Chem 2014;289:23020-23028.

58. Wagener J, Malireddi RK, Lenardon MD, Köberle M, Vautier S, MacCallum DM, Biedermann T, Schaller M, Netea MG, Kanneganti TD, et al. Fungal chitin dampens inflammation through IL-10 induction mediated by NOD2 and TLR9 activation. PLoS Pathog 2014;10:e1004050.

59. Kumirska J, Czerwicka M, Kaczyński Z, Bychowska A, Brzozowski K, Thöming J, Stepnowski P. Application of spectroscopic methods for structural analysis of chitin and chitosan. Mar Drugs 2010;8: 1567-1636.

60. Schmatz DM, Powles MA, McFadden D, Nollstadt K, Bouffard FA, Dropinski JF, Liberator P, Andersen J. New semisynthetic pneumocandins with improved efficacies against Pneumocystis carinii in the rat. Antimicrob Agents Chemother 1995;39:1320-1323.

61. Schmatz DM, Romancheck MA, Pittarelli LA, Schwartz RE, Fromtling RA, Nollstadt KH, Vanmiddlesworth FL, Wilson KE, Turner MJ. Treatment of Pneumocystis carinii pneumonia with 1,3- $\beta$-glucan synthesis inhibitors. Proc Natl Acad Sci USA 1990;87:5950-5954.

62. Clemons KV, Stevens DA. Efficacy of nikkomycin Z against experimental pulmonary blastomycosis. Antimicrob Agents Chemother 1997;41:2026-2028.

63. Shubitz LF, Trinh HT, Perrill RH, Thompson CM, Hanan NJ, Galgiani JN, Nix DE. Modeling nikkomycin Z dosing and pharmacology in murine pulmonary coccidioidomycosis preparatory to phase 2 clinical trials. J Infect Dis 2014;209:1949-1954.

64. Brown GD, Denning DW, Gow NA, Levitz SM, Netea MG, White TC Hidden killers: human fungal infections. Sci Trans/ Med 2012;4:165rv13.

65. Lobo ML, Esteves F, de Sousa B, Cardoso F, Cushion MT, Antunes F, Matos $O$. Therapeutic potential of caspofungin combined with trimethoprim-sulfamethoxazole for Pneumocystis pneumonia: a pilot study in mice. PLoS One 2013;8:e70619. 
66. Masuoka J. Surface glycans of Candida albicans and other pathogenic fungi: physiological roles, clinical uses, and experimental challenges. Clin Microbiol Rev 2004;17:281-310.

67. Netea MG, Brown GD, Kullberg BJ, Gow NA. An integrated model of the recognition of Candida albicans by the innate immune system. Nat Rev Microbiol 2008;6:67-78.

68. Chaffin WL, López-Ribot JL, Casanova M, Gozalbo D, Martínez JP. Cell wall and secreted proteins of Candida albicans: identification, function, and expression. Microbiol Mol Biol Rev 1998;62:130-180.

69. Plaine A, Walker L, Da Costa G, Mora-Montes HM, McKinnon A, Gow NA, Gaillardin C, Munro CA, Richard ML. Functional analysis of Candida albicans GPI-anchored proteins: roles in cell wall integrity and caspofungin sensitivity. Fungal Genet Biol 2008;45:1404-1414.

70. Verghese GM, Gutknecht MF, Caughey GH. Prostasin regulates epithelial monolayer function: cell-specific Gpld1-mediated secretion and functional role for GPI anchor. Am J Physiol Cell Physiol 2006; 291:C1258-C1270.

71. Richard ML, Plaine A. Comprehensive analysis of glycosylphosphatidylinositol-anchored proteins in Candida albicans. Eukaryot Cell 2007;6:119-133.

72. Kottom TJ, Thomas CF Jr, Limper AH. Characterization of Pneumocystis carinii PHR1, a pH-regulated gene important for cell wall integrity. J Bacteriol 2001;183:6740-6745.
73. Ghannoum MA, Spellberg B, Saporito-Irwin SM, Fonzi WA. Reduced virulence of Candida albicans PHR1 mutants. Infect Immun 1995;63: 4528-4530.

74. Porta A, Ramon AM, Fonzi WA. PRR1, a homolog of Aspergillus nidulans palF, controls $\mathrm{pH}$-dependent gene expression and filamentation in Candida albicans. J Bacteriol 1999;181: 7516-7523.

75. Brown K, Pompeo F, Dixon S, Mengin-Lecreulx D, Cambillau C, Bourne Y. Crystal structure of the bifunctional $\mathrm{N}$-acetylglucosamine 1-phosphate uridyltransferase from Escherichia coli: a paradigm for the related pyrophosphorylase superfamily. EMBO J 1999;18: 4096-4107.

76. Marks DL, Wu K, Paul P, Kamisaka Y, Watanabe R, Pagano RE. Oligomerization and topology of the Golgi membrane protein glucosylceramide synthase. J Biol Chem 1999;274:451-456.

77. Zhu C, Wang M, Wang W, Ruan R, Ma H, Mao C, Li H. Glucosylceramides are required for mycelial growth and full virulence in Penicillium digitatum. Biochem Biophys Res Commun 2014;455: 165-171.

78. Rittershaus PC, Kechichian TB, Allegood JC, Merrill AH Jr, Hennig M, Luberto C, Del Poeta M. Glucosylceramide synthase is an essential regulator of pathogenicity of Cryptococcus neoformans. J Clin Invest 2006;116:1651-1659. 